\title{
STABILITY AND CALIBRATING METHODS OF SOME THIN FILM PLATINUM THERMOMETERS IN THE RANGE 13.8-273.16 K
}

\author{
J. K. Georgiev, D. A. Dimitrov, A. L. Zahariev \\ Bulgarian Academy of Sciences, Institute of Solid State Physics, \\ 72 Tzarigradsko Chaussee, 1784 Sofia, Bulgaria \\ (Received September 30, 1999)
}

\begin{abstract}
Resistance stability of thin film platinum resistance thermometers produced by PRIBOR Ltd., Koprivshtitza, Bulgaria was investigated 30 months after their thermal stabilization. A threepoint calibration method for the range between $13.8 \mathrm{~K}$ and $273.16 \mathrm{~K}$ is proposed. The optimum conditions necessary for an adequate individual calibration of the investigated sensors are defined. Mathematical descriptions of the $T(R)$ and the $R(T)$ functions between $13.8 \mathrm{~K}$ and $273.16 \mathrm{~K}$ are suggested using a new weighted least squares method.
\end{abstract}

Key words: mathematical description, thermometers, calibration.

PACS numbers: 89.20.+d, 06.20.-f, 07.20.-n

\section{INTRODUCTION}

The interest in industrial platinum resistance thermometers (IPRTs) arose recently [1]. There are three types of IPRTs - wire, thin film and thick film thermometers. The thin film platinum resistance thermometers (TPRTs) have some indisputable advantages such as small dimensions, high response, easy fabrication and relatively low cost [2]. They can be used without any calibration in the range of $70-200 \mathrm{~K}$ following the $T(R)$ and $R(T)$ common descriptions with an accuracy of $\pm(1-2)$ $\mathrm{K}$ and $\pm(0.4-0.8) \Omega$, respectively [3]. A two-point calibration method allows to apply them in the range of $70-200 \mathrm{~K}$ with an accuracy of $\pm 0.1 \mathrm{~K}$ or $\pm 0.04 \Omega$ [3]. Their main disadvantages are:

i) a shift of the $R(T)$ function after a thermal cycling below $200 \mathrm{~K}$, and

ii) individual $R(T)$ and $T(R)$ functions for any particular sensor.

Therefore TPRTs can be used for precise measurements below $200 \mathrm{~K}$ after an adequate stabilization and an individual calibration [3], [4].

The task of the present work was to investigate the resistance stability of TPRTs, produced by PRIBOR Ltd., Koprivshtitza, Bulgaria under a technology described in [5] and their $T(R)$ and $R(T)$ functions in the temperature range $13.8-273.16 \mathrm{~K}$ in order to define:

i) period of stability of TPRTs after their thermal stabilization,

ii) the optimum conditions for an adequate individual calibration of the investigated sensors, and

iii) suitable mathematical descriptions in polynomial form for $T(R)$ and $R(T)$ functions.

For this reason 10 TPRTs selected randomly from different series and numbered from 031 to 042 save 037 and $039)$ have been investigated. Sensors 037 and 039 were [4] and became unusable. Investigations were carried out on a computerized experimental setup. The experimental method and the setup were fully described in [4] and [6].

\section{STABILITY OF THE INVESTIGATED SENSORS}

The problem of TPRTs characteristic stabilization was a subject of our previous paper [4]. It was found out that they remained stable at least 5 months after their stabilization. Now we carried out 6 new thermal cycles numbered from 38 to 43 - once between 10 and $300 \mathrm{~K}$ (helium cycle) and 5 times between $65 \mathrm{~K}$ and $300 \mathrm{~K}$. The helium cycle included 12 cycles between 5 and $75 \mathrm{~K}$ as it was done through the $16^{\text {th }}$ cycle (see about it in [4]. The sensor 032 resistance variance at 6 fixed temperatures after every single thermal cycle including the described in [4] is shown in Fig. 1. The results for all other sensors are analogous. It is well seen that the resistance stabilizes after cycle No 27 . The resistance variance from $28^{\text {th }}$ to $43^{\text {th }}$ cycles was less than TPRTs accuracy [3] and the experimental error [4].

\section{MATHEMATICAL DESCRIPTION OF THE INDIVIDUAL $T(R)$ AND $R(T)$ FUNCTIONS}

It was established in [3] that the TPRTs can be used as thermometers in the range $13.8-273.16 \mathrm{~K}$ with an accuracy of $\pm(5-6) \mathrm{mK}$. Having in mind those results we have searched for a mathematical description that could describe the calibration results with the respective accuracy. For this purpose a weighted least squares method was developed. It was based on the well known methodology described in Refs.7 and 8. The basic functions $P_{k}(x)$ used by the Chi-square function [7] can be:

i) power functions

$$
P_{k}(x)=x^{k-1}
$$


ii) power functions orthogonalized on variable interval $-1.0-+1.0$,

iii) Chebyshev Polynomials,

iv) Displaced Chebyshev Polynomials, and

v) Orthogonal Polynomials (normalized or not) made up for every data points set using a well known threeterm recurrence procedure for generating orthogonal polynomials [8], [9], [10].

The fitted functions are ordinary polynomials of the type

$$
Y(y)=\sum_{i=1}^{M} B_{i}[X(x)]^{i-1},
$$

where $Y(y)$ and $X(x)$ can be as follows:

$$
\begin{gathered}
Y=y, \\
Y=1 / y, \\
Y=\ln (y), \\
Y=e^{y},
\end{gathered}
$$

$$
Y=y^{m}
$$

and

$$
\begin{gathered}
X=x, \\
X=1 / x, \\
X=\ln (x), \\
X=e^{x}, \\
X=x / a+b,
\end{gathered}
$$$$
X=[\ln (x / a+b)+c] / d
$$$$
X=\left[(x / a+b)^{m}+c\right] / d,
$$

Here $a, b, c, d$ and $m$ are free coefficients $(a \neq 0$ and $d \neq 0)$ and $M$ is polynomial number of terms. Eqs.(3) and Eqs.(4) allow to investigate a large number of polynomial types.
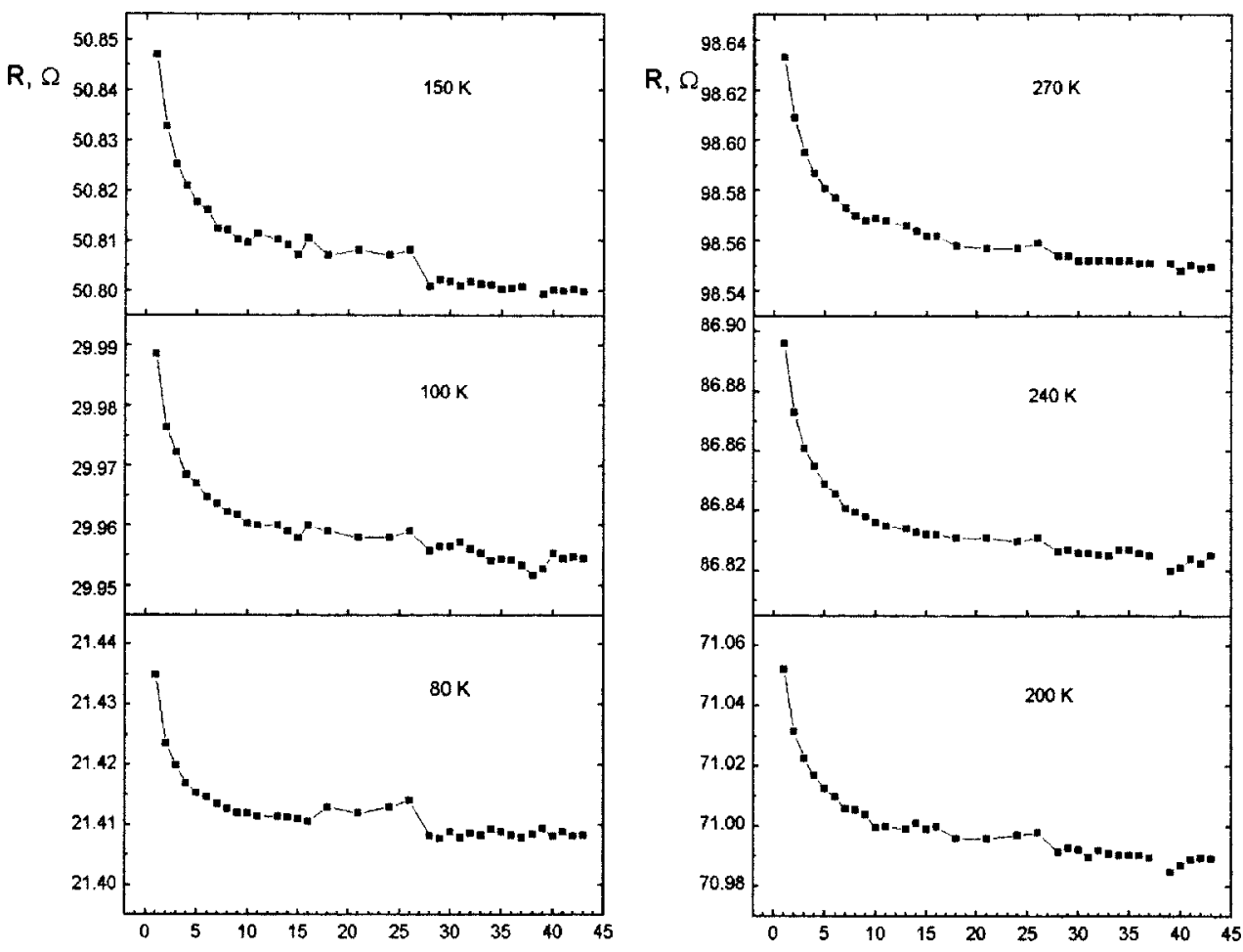

Number of Cycles

Fig. 1. Dependence of resistance on thermal cycle number for six temperatures for sensor 032. 
Software realizing the method was written in Borland Pascal 7.0. It calculates:

i) the polynomial coefficients $-B_{i}$,

ii) the standard deviation $-\sigma$,

iii) the Chi-square $-\chi^{2}$,

iv) the normalized value of Chi $-\chi_{n}$,

v) the maximal deviation,

vi) the optimum polynomial number of terms, and

vii) the standard deviation dependence on number of terms $-\sigma(M)$, where

$$
\begin{gathered}
\sigma=\left[\sum_{I=1}^{N}\left[y_{i}-y\left(x_{i}\right)\right]^{2} /(N-M)\right]^{1 / 2}, \\
\chi_{n}=\left[\chi^{2} /(n-M)\right]^{1 / 2} .
\end{gathered}
$$

Here $y_{i}$ is a measured value of $y$ (experimental data), $y\left(x_{i}\right)$ is the fitted value for the same data point and $N$ is number of the experimental points.

The program allows also to present graphically the fitted function $-Y(X)$, its first and second derivatives $Y^{\prime}(X)$ and $Y^{\prime \prime}(X)$ and the dependence $\Delta Y(Y)$, where $\Delta Y=y_{i}-y\left(x_{i}\right)$. Thus, one can control visually if the fitted function is a smooth curve or any oscillations occur.

The main feature of the method is the possibility to does the fitting procedure using iteratively two criteria:

i) the minimization of funcion Chi-square $-\chi^{2}$ and

ii) the fulfillment for all data points of the inequality

$$
\rho\left(x_{i}\right)\left[y_{i}-y\left(x_{i}\right)\right]^{2} \leq 1
$$

where $\rho\left(x_{i}\right)$ is the weight of the $i^{\text {th }}$ experimental point. This principle of minimization is proposed in [11] (see also [12] and [13]). Our program defines the suitable weight - $\rho\left(x_{i}\right)$ for all data points according to inequality Eq.(7) after every fit and then do the next fit. The iterative process stops when the normalized value of Chi $\chi_{n}$ stabilizes. This method eliminates the "bad" points influence and improves the physical authenticity of the fitted curve. The new moment in the proposed method is that there is a possibility to apply a bigger initial weight $\left(\rho\left(x_{i}\right) \geq 3.33\right)$ for some data points which remains constant through the fitting process.

This program routine was applied in our investigations to define the suitable polynomial type and the optimal number of terms for the fitted functions.

The experimental data between $11 \mathrm{~K}$ and $320 \mathrm{~K}$ from all the carried out investigations after the thermal stabilization (cycles 28-43) were fitted. At least 12 calibration points were available at every temperature level. All the fits were carried out with the initial data points weight $\rho\left(x_{i}\right)=1$ for the most part of the experimental data because they were obtained with the same accuracy [4]. Exceptions were done in two cases:

i) for the data at the edges of the investigated temperature range according to Hamming's recommendations [8] (mainly the range 14-25 K because of the low accuracy of the data below $14 \mathrm{~K}$ ), and ii) when it was necessary to correct the fitted curve in some region. We had such problems in the range of 25-50 K for some $T(R)$ functions.

The fitting procedure was made applying all the above said basic functions $-P_{k}$ and polynomial types (Eqs.(3) and Eqs.(4)). The best results were obtained with the orthogonal polynomials basic functions (normalized or not) orthogonalized on variable interval $-1.0-+1.0$. There was no difference between them for polynomial fits with the number of terms up to 21 but the calculations with Chebyshev polynomials and orthogonalized Power functions (Eq.(1)) were simpler because there was no necessity to calculate the coefficients of a three-term recurrence [8], [9], [10]. The normalization of orthogonal polynomials did not lead to better results but made the calculations more complicated. For this reason it is preferable to use in the least squares fits Chebyshev polynomials or Power functions orthogonalized on variable interval $1.0-+1.0$ as they are the simplest systems of orthogonal polynomials.

The use of simple basic functions and the possibility to apply a bigger initial weight for any of the data points are the main advantages of this method in comparison with the OPEM method [11]. Moreover there is no necessity to estimate previously the absolute resistance resolution to determine the initial data points weight. These features make our method simpler and more universal. We fitted the commercially available test data obtained under specified operating conditions by Lake Shore Cryotronics for the Platinum thermometer (model Pt-103, Serial No P3170) investigated in Refs.12 and 13 to compare the proposed method, the standard Chebyshev and the OPEM method [11]. The results for $T(R)$ function obtained with our program (standard Chebyshev and weighted Chebyshev - new method) and those from Refs.12 and 13 for OPEM are shown in Table 1. It is well seen that the results obtained with our method and OPEM are very close and excel the standard Chebyshev fit.

The fitting procedure results allowed us to propose the following ordinary polynomials to describe the individual $T(R)$ and $R(T)$ functions of TPRTs in the temperature range $13.8-273.16 \mathrm{~K}$

$$
\begin{gathered}
T=\sum_{I=1}^{M} A_{i}\left\{\left[\left(R / R_{o}\right)^{1 / 6}-0.65\right] / 035\right\}^{i-1} \\
W=R / R_{o}=\sum_{I=1}^{M} B_{i}\left\{\left[\left(T / T_{o}\right)^{1 / 6}-0.65\right] / 035\right\}^{i-1}
\end{gathered}
$$

where $A_{i}$ and $B_{i}$ were polynomial coefficients, $T_{o}=$ $273.16 \mathrm{~K}$ and $R_{0}$ was the value of $R$ at $T=T_{0}$. $R_{o} \approx 100 \Omega$ for the investigated sensors and the fit could be made using the value $R_{0}=100$ which leads to a negligible error. Eqs.(8) and (9) are similar to the inverse formula for platinum thermometer reference $T(R)$ function of ITS -90 [14]. 


\begin{tabular}{||c|c|c|c|r|r||}
\hline \hline $\begin{array}{c}\text { Temperature } \\
\text { range, } \mathrm{K}\end{array}$ & $\begin{array}{c}\text { Number } \\
\text { of points }\end{array}$ & $\begin{array}{r}\text { Number } \\
\text { of terms }\end{array}$ & Fit type & $\begin{array}{r}\text { Standard } \\
\text { deviation, } \\
\text { mK }\end{array}$ & $\begin{array}{r}\text { Maximum } \\
\text { deviation, } \\
\mathrm{mK}\end{array}$ \\
\hline \hline $11-31$ & 19 & 11 & Chebyshev & 7.4 & -11.9 \\
& & 11 & OPEM & 6.6 & -19.8 \\
& & 11 & New method & 7.0 & -14.9 \\
& & 12 & New method & 4.2 & -11.1 \\
\hline $31-95$ & 20 & 8 & Chebyshev & 9.7 & -19.9 \\
& & 8 & OPEM & 5.5 & -15.2 \\
& & 8 & New method & 3.8 & -23.3 \\
\hline $95-325$ & 27 & 9 & Chebyshev & 2.0 & -3.5 \\
& & 9 & OPEM & 1.6 & 3.9 \\
& & 9 & New method & 2.0 & -3.5 \\
\hline $14-325$ & 56 & 18 & Chebyshev & 11.9 & -27.3 \\
& & 18 & OPEM & 5.8 & 20.9 \\
& & 18 & New method & 4.2 & -45.1 \\
\hline \hline
\end{tabular}

Table 1. Comparative results between OPEM, standard Chebyshev fit and new weighted method for $T(R)$ function of Platinum thermometer model PT-103 Ser.No P3170.

\begin{tabular}{||l|l|c|l||}
\hline \hline Function type & $\begin{array}{l}\text { Temperature } \\
\text { range, } \mathrm{K}\end{array}$ & $\begin{array}{c}\text { Polynomial } \\
\text { number of } \\
\text { terms }\end{array}$ & $\begin{array}{l}\text { Standard } \\
\text { deviation, } \\
\mathrm{mK} \text { or } \mathrm{m} \Omega\end{array}$ \\
\hline \hline$T(R)$ function - Eq.(8) & $13.8-70.0$ & $15-16$ & $1.5-2.5 \mathrm{mK}$ \\
$T(R)$ function - Eq.(8) & $70.0-273.16$ & $9-10$ & $3.0-5.0 \mathrm{mK}$ \\
$T(R)$ function - Eq.(8) & $13.8-273.16$ & $17-18$ & $3.0-5.0 \mathrm{mK}$ \\
$R(T)$ function - Eq.(10) & $13.8-70.0$ & $10-11$ & $0.5-1.5 \mathrm{~m} \Omega$ \\
$R(T)$ function - Eq.(9) & $70.0-273.16$ & $8-10$ & $1.5-2.5 \mathrm{~m} \Omega$ \\
$R(T)$ function - Eq.(9) & $13.8-273.16$ & $14-16$ & $1.5-2.5 \mathrm{~m} \Omega$ \\
\hline \hline
\end{tabular}

Table 2. Recommended number of polynomial terms (coefficients) for the investigated temperature ranges.

It was found out that any equation of the types $T=$ $F(\ln R)$ and $R=f(\ln T)$ could not be applied for to describe TPRTs produced by PRIBOR Ltd in most cases instead of Eqs.(8) and (9) unlike the wire Platinum resistors. No correction functions were necessary to Eqs.(8) and (9) as recommended in [15] because they described the experimental data with an adequate accuracy (see Table 1 and [3]).

Equations (8) and (9) can be applied to describe $T(R)$ and $R(T)$ functions in the "nitrogen" interval 70-273.16 $\mathrm{K}$ and $T(R)$ functions in the lower range $13.8-70 \mathrm{~K}$. Conventional polynomials

$$
W=R / R_{o}=\sum_{I=1}^{M} B_{i} T^{i-1},
$$

describe the $R(T)$ functions in this range $(13.8-70 \mathrm{~K})$ and up to $90 \mathrm{~K}$ better than Eq.(9).

The recommended numbers of polynomial terms for the investigated temperature ranges and the respective standard deviations are shown in Table 1 . They were defined using:

i) the dependency of polynomial standard deviation on the number of terms for every sensor $\left(\sigma_{T}(M)\right.$ and $\left.\sigma_{R}(M)\right)$

ii) the derivatives $d T / d R$ and $d R / d T$ and

iii) the dependence of the residuals between the polynomial description and the experimental data on temperature $-\Delta T(T)$ or $\Delta R(T)$.

The $\sigma_{T}(M)$ and $\sigma_{R}(M)$ dependences allowed to define the values of $M$ at which the $\sigma_{T}$ and $\sigma_{R}$ values corresponded to the data on TPRTs accuracy presented in [3]. The $\sigma_{T}(M)$ and $\sigma_{R}(M)$ dependences for five thermometers for the investigated temperature ranges $(13.8-70 \mathrm{~K}$. $70-273.16 \mathrm{~K}$ and $13.8-273.16 \mathrm{~K})$ are shown in Figs. 2a, $2 \mathrm{~b}$ and $2 \mathrm{c}$.

The derivatives $d T / d R$ and $d R / d T$ were investigated after every fit to verify if oscillations occur. The derivatives $d T / d R$ for sensor 032 and $d R / d T$ for sensor 041 are shown in Fig. 3. The polynomial numbers of terms are 18 for the $T(R)$ function and 15 for the $R(T)$ function. It is well seen that they are smooth curves with the maximum or minimum at $T \approx 85-86 \mathrm{~K}$. The second derivatives are also smooth curves and they are equal to 0 at $T \approx 85-86 \mathrm{~K}$. The derivatives of lower or higher power polynomials in comprarison with those recommended in Table 2 (1-3 degrees less or 2-4 higher) are not smooth curves. 

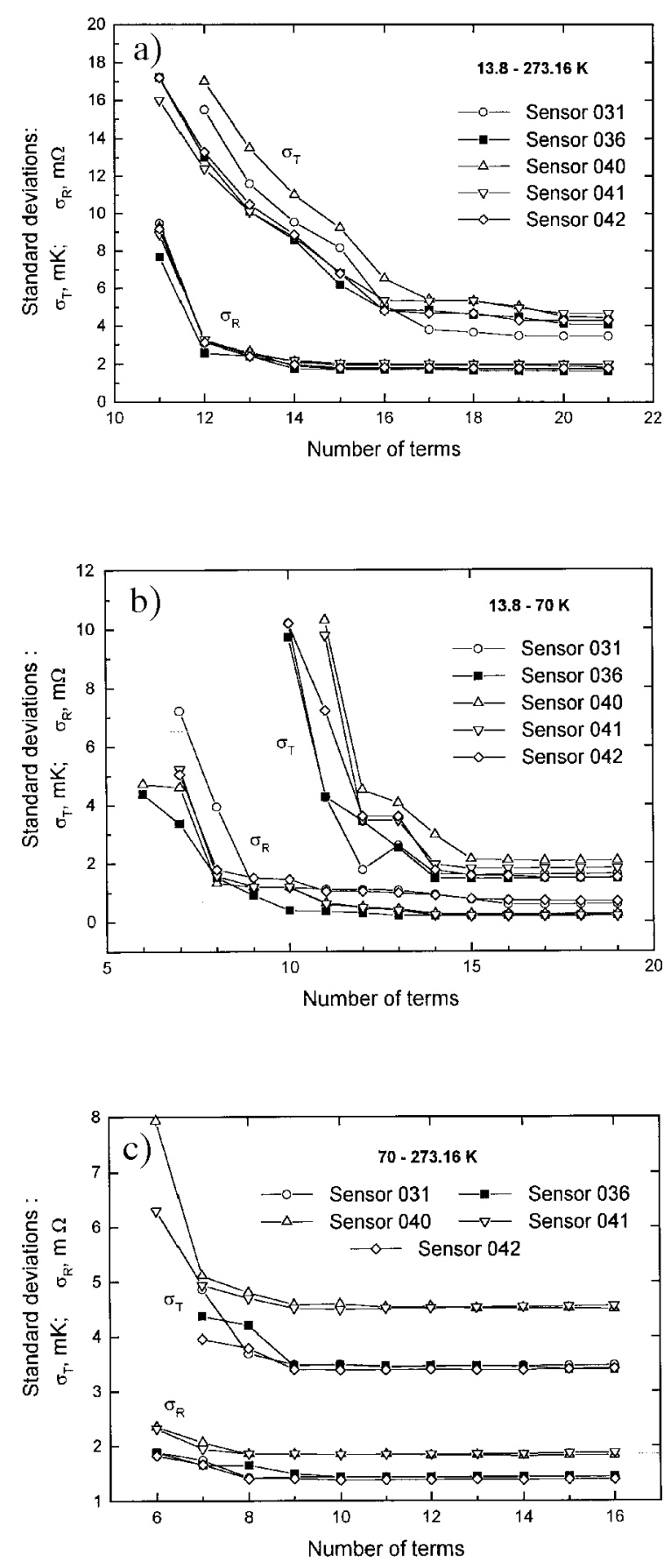

Fig. 2. Dependence of polynomial standard deviations $\sigma_{T}$ and $\sigma_{R}$ on number of polynomial terms for sensors 031,036 , 040, 041 and 042: 2a - Temperature range 13.8-273.16 K; $2 \mathrm{~b}$ - Temperature range $13.8-70 \mathrm{~K} ; 2 \mathrm{c}$ - Temperature range 70-273.16 K.

That is why, the application of higher or lower power polynomials than recommended in Table 2 is not admissible because oscillations of the fitted function can occur. So, one can assume that the proposed mathematical descriptions of $T(R)$ and $R(T)$ functions for the TPRTs can be applied in practice. This conclusion is confirmed also by the character of dependence of the residuals between the polynomial descriptions and the experimental data on the temperature $-\Delta T(T)$ and $\Delta R(T)$. The dependences $\Delta T(T)$ for sensor 033 and $\Delta R(T)$ for sensor 034 are shown in Figs. 4a and 4b. The recommended polynomial types and number of terms are applied to obtain them (see Table 1). It is well seen that the residuals $\Delta T_{i}$ and $\Delta R_{i}$ are less than $\pm 6 \mathrm{mK}$ and $\pm 2.5 \mathrm{~m} \Omega$, respectively, for the most part of the experimental data and the data points are situated regularly on both sides of the fitted curve and no oscillations are detected.

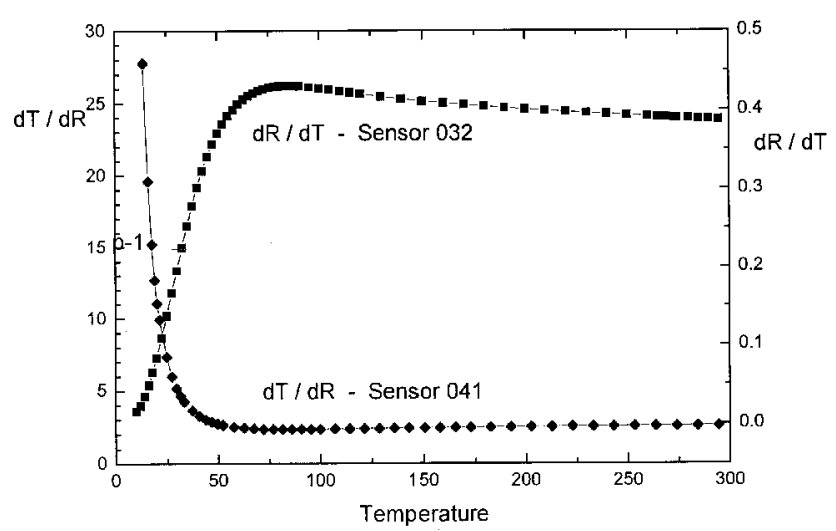

Fig. 3. Dependence on temperature of the derivatives $d T / d R$ for sensor 032 and $d R / d T$ for sensor 041 .

\section{CALIBRATION METHODS}

It is well known that thermometer calibration must be realized at a sufficient number of temperature levels but the number of calibration points depends on the applied method.

Two calibration points are enough to calibrate the TPRTs in the range of $70-273.16 \mathrm{~K}$ with an accuracy of $\pm 0.1 \mathrm{~K}$ or $\pm 0.04 \Omega$ [3]. The two-point calibration method is based on the linearity of the dependences $\Delta W_{j}(T)$ and $\Delta T_{j}(W)$ above $70 \mathrm{~K}$ and on the description of the thermometer characteristics by the sum of reference and deviation functions as known for the standard platinum thermometers [14]. $\Delta W_{j}(T)$ is the difference between $W_{j}(T)$ and $W_{c}(T)$, and $\Delta T_{j}(W)$ is the difference between $T_{j}(W)$ and $T_{c}(W)$ of TPRTs above $70 \mathrm{~K}$, respectively. $W_{j}(T)$ and $T_{j}(W)$ are functions of the $j^{\text {th }}$ thermometer. The common mathematical descriptions $T_{c}(W)$ and $W_{c}(T$, defined in [3] are used as reference functions. The $T(W)$ and $W(T)$ functions of any TPRT can be used as $T_{c}(W)$ and $W_{c}(T)$ but it is preferable to select a TPRT whose parameters are in the vicinity of the statistically average for the investigated group of sensors [3].

The two-point calibration method can be developed to a three-point method to expand the temperature range of the calibration down to $13.8 \mathrm{~K}$. The three-point calibration method is also based on the description of the thermometer characteristics by the sum of reference and deviation functions. It ensures the accuracy of $\pm 0.04 \Omega$ 
( $\pm 0.1 \mathrm{~K}$ above $45 \mathrm{~K}$ and $\pm 0.3 \mathrm{~K}$ below $45 \mathrm{~K}$ ) in the range of $13.8-273.16 \mathrm{~K}$. The calibration points have to be: $T_{1}=$ $270-280 \mathrm{~K}, T_{2}=75-80 \mathrm{~K}$ and $T_{3}=4.2-10 \mathrm{~K}$. We recommend the first calibration point to be at $273.16 \mathrm{~K}$ (water triple point) because it is obligatory to determine $R_{o}$ of any TPRT at this temperature. The recommended value of $T_{2}$ is $77.36 \mathrm{~K}$ (liquid Nitrogen boiling point). The liquid Nitrogen boiling point is preferable because it can be realized easier than any other temperature in the range $(75-80 \mathrm{~K})$. The proposed $T_{3}$ value is $10 \mathrm{~K}$ because the use of a lower value decreases slightly the accuracy of Eq.(11). $W$ and $R$ of TPRTs are almost constant below $10-11 \mathrm{~K}$ because this is the region of the residual resistance of the TPRTs. The deviation is less than 3. For this reason the curves of $W_{j}(T)$ functions are parallel and $\Delta W_{j}(T) \approx$ const. Therefore $W_{3}$ can be defined at any temperature below $10 \mathrm{~K}$, including in liquid helium at $4.2 \mathrm{~K}$, and $T_{3}$ can be accepted to be $10 \mathrm{~K}$.
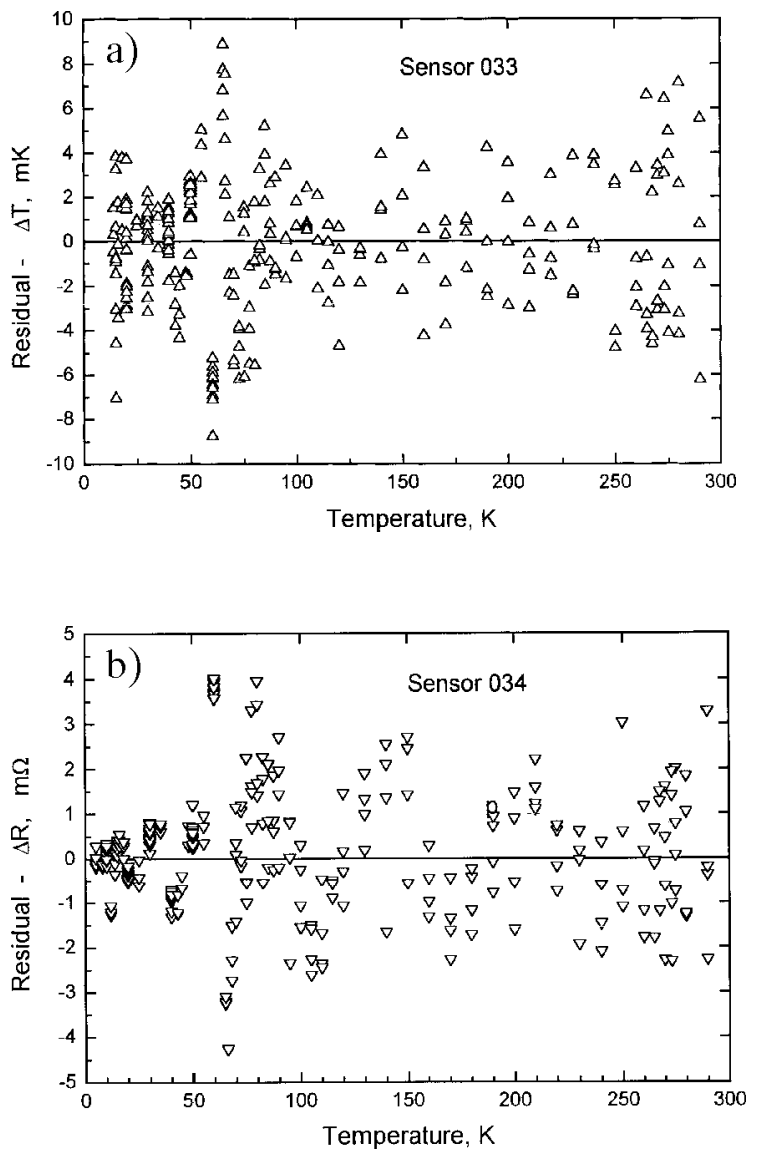

Fig. 4. Dependence of residuals between the polynomial descriptions and the experimental data on temperature: 3a $-\Delta T(T)$ for sensor 033 ; $3 \mathrm{~b}-\Delta R(T)$ for sensor 034 .

The $W(T)$ and $T(W)$ functions are the same as for the two-point calibration method

$$
\begin{aligned}
& W_{j}(T)=W_{c}(T)+\Delta W_{j}(T), \\
& T_{j}(W)=T_{c}(W)+\Delta T_{j}(W) .
\end{aligned}
$$

The $W(T)$ and $T(W)$ functions (Eqs. (8) and (9)) of sensor 031 were used as reference functions because the common mathematical descriptions [3] could not be applied below $70 \mathrm{~K}$ and the parameters of sensor 031 were in the vicinity of statistical mean for the investigated group of sensors. It is well seen from Fig. 5 where the dependences on temperature of the differences $\Delta W_{j}$ between the experimental $W_{j}$ data of all investigated TPRTs and the $W$ of sensor 031 in the range $5-320 \mathrm{~K}$ are shown.

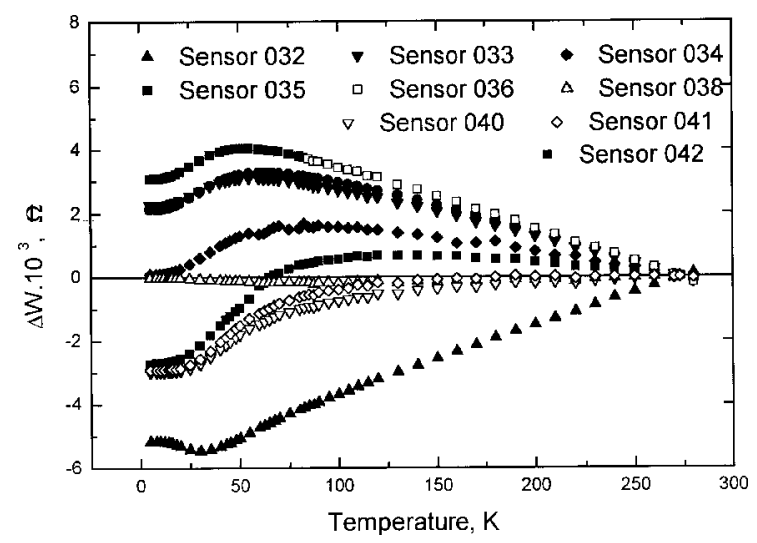

Fig. 5. Dependences on temperature of the differences $\Delta W_{j}$ between the experimental $W_{j}$ data and $W$ of sensor 031 in the range $5-320 \mathrm{~K}$ for all thermometers.

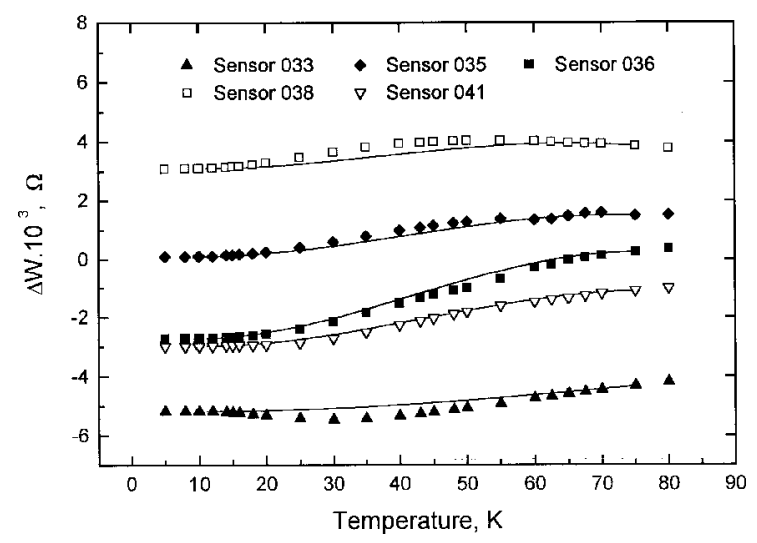

Fig. 6. The deviation functions $\Delta W_{j}(T)$ according to Eq.(15) for sensors 033, 035, 036, 038 and 041 in the range 10-77.4 $\mathrm{K}$ and the experimental data points. 
The deviation functions $\Delta W_{j}(T)$ and $\Delta T_{j}(W)$ above $T_{2}$ are the same as for the two-point method [3]

$$
\begin{gathered}
\Delta W_{j}(T)=\Delta W_{j}\left(T_{2}\right)\left(T_{0}-T\right) /\left(T_{0}-T_{2}\right)=Z_{W} \Delta W_{j}\left(T_{2}\right), \\
\Delta T_{j}(W)=\Delta T_{j}\left(W_{2}\right)(1-W) /\left(1-W_{2}\right)=Z_{T} \Delta T_{j}\left(W_{2}\right) .
\end{gathered}
$$

Here $T_{0}$ and $T_{2}$ are the first and the second calibration temperature levels $\left(T_{0}=T_{1}=273.16 \mathrm{~K}\right)$ and $Z_{T}$ and $Z_{W}$ are the functions first suggested by Cragoe [16] and used later by Besley and Kemp for their two-points method [1]. The deviation functions $\Delta W_{j}(T)$ can be defined as 4 — terms polynomials below $T_{2}$

$$
\Delta W_{j}(T)=\sum_{i=1}^{4} D_{i} T^{i-1}
$$

Unfortunately, the deviation functions $\Delta T_{j}(W)$ could not be defined properly below $T_{2}$. It is a consequence of the fact that the differences between $T_{j}(R)$ functions of these sensors below $25 \mathrm{~K}$ became too large $\left(\Delta T_{j}^{\prime}(W) \rightarrow \infty\right.$ below $\left.10 \mathrm{~K}\right)$ and an adequate mathematical description of $\Delta T_{j}(W)$ could not be found. For this reason Eqs. (11), (9) and (15) have to be used to define $T$ below $T_{2}$. It is the main disadvantage of the threepoint method. As a consequence the reference functions $W_{c}(T)$ and $T_{c}(W)$ were defined in the ranges 11-300 $\mathrm{K}$ and $70-300 \mathrm{~K}$ respectively using the proposed fitting method. The numbers of terms were $M=15$ for the $W_{c}(T)$ function (Eq.(9)) and $M=9$ for the $T_{c}(W)$ function (Eq.(8)).

The Eq.(15) coefficients $D_{i}$ can be calculated as follows. The values of $T$ and $W$ at the second and third calibration points of the calibrated TPRT and Eqs. (11) and (13) allow to write the equations

$$
\begin{aligned}
& D_{4} T_{2}^{3}+D_{3} T_{2}^{2}+D_{2} T_{2}+D_{1}=W_{2}-W_{c}\left(T_{2}\right), \\
& D_{4} T_{3}^{3}+D_{3} T_{3}^{2}+D_{2} T_{3}+D_{1}=W_{3}-W_{c}\left(T_{3}\right),
\end{aligned}
$$

where $W_{3}$ is the value of $W_{j}$ at the temperature $T_{3}$.

It was shown that $\Delta W_{j}(T) \approx$ const below $10-11 \mathrm{~K}$. For this reason the first derivative of Eq.(15) is equal to 0 at $T=T_{3}$

$$
\Delta W_{j}^{\prime}\left(T_{3}\right)=3 D_{4} T_{3}^{2}+2 D_{3} T_{3}+D_{2}=0
$$

The first derivative of Eq.(15) is obviously equal to the derivative value of Eq.(13) at $T=T_{2}$ because this is the common point of the two functions that describe the $\Delta W_{j}(T)$ functions above and below $T_{2}$ and here their derivatives must be identical. For this reason one can write the following equation

$$
3 D_{4} T_{2}^{2}+2 D_{3} T_{2}+D_{2}=-\Delta W_{j}\left(T_{2}\right) /\left(T_{0}-T_{2}\right)
$$

Now the coefficients $D_{i}$ can be calculated from the system of equations (16), (17), (18) and (19).

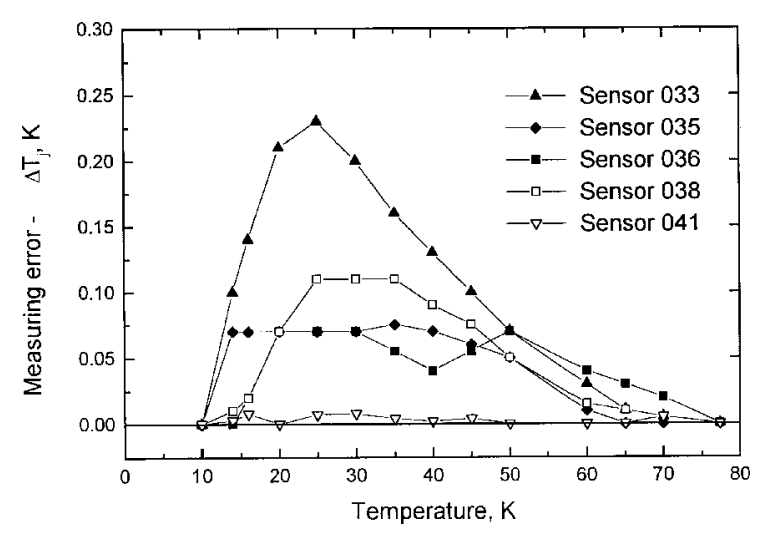

Fig. 7. The differences $\Delta T_{j}(T)$ between calculated Eq.(11) and experimental results for sensors 033, 035, 036, 038 and 041 .

The adequacy of three-points calibration method in the region of $13.8-77.4 \mathrm{~K}$ (below $T_{2}$ ) is illustrated in Figs. 6 and 7 for 5 sensors using the above said experimental data (cycles 28-43). The values of $\Delta W_{j}(T)$ according to Eqs.(11) and (15) and the experimental data are shown in Fig. 6 for sensors 033, 035, 036, 038 and 041. The differences $\Delta T_{j}(T)$ between the calculated and experimental results for the same sensors in the same temperature region are shown in Fig.7. The analysis of these data allowed to ascertain that an accuracy better than $\pm 0.04 \Omega( \pm 0.1 \mathrm{~K}$ above $45 \mathrm{~K}$ and $\pm 0.3 \mathrm{~K}$ below $45 \mathrm{~K})$ was achieved. The accuracy below $45 \mathrm{~K}$ can be better than $\pm 0.1 \mathrm{~K}$ if the value of $W_{3}-W_{c}\left(T_{3}\right)$ is small (sensors 035,036 and 038 for example). For this reason it is preferable to classify the sensors into $2-3$ groups in accordance with their residual resistance $-W_{3}$ when industrial quantities of sensors has to be calibrated. Every group of sensors must possess its own reference function - $W_{c}(T)$. As said above, $W(T)$ function of any sensor can be used as $W_{c}(T)$ but the most suitable for this purpose can be any sensor whose residual resistance $-W_{3}$ 
is in the vicinity of the statistically mean for the group. It has to be calibrated precisely in the range $13.8-300 \mathrm{~K}$.

\begin{tabular}{||c|c||}
\hline \hline Temperature & Temperature \\
range, $\mathrm{K}$ & steps, $\mathrm{K}$ \\
\hline \hline Below 16 & $0.5-1.0$ \\
$16-25$ & $1.0-2.0$ \\
$25-90$ & $2.0-2.5$ \\
$90-120$ & 5.0 \\
$120-260$ & 10.0 \\
$265-275$ & 2.5 \\
Above 280 & 10.0 \\
\hline \hline
\end{tabular}

Table 3. Recommended steps between the temperature levels for precise TPRTs calibration.

The precise calibration of TPRTs requires considerably more than 3 calibration points and an adequate mathematical description to ensure their maximum accuracy. It was ascertained that the steps between calibration temperature levels had to be as shown in Table 3 . These results were based on the fitting results described in Section 3. The application of larger steps did not allow sometimes to obtain smooth curves for higher power polynomials.

\section{CONCLUSIONS}

The investigated thermometers were selected at random from different series. Therefore we consider that the sensor stability results, the proposed calibration methods and the mathematical descriptions of $T(R)$ and $R(T)$ functions are valid for all the TPRTs produced by PRIBOR Ltd as well as for the sensors manufactured under analogous technologies.

The results confirmed one more time that these sensors can be used in the temperature range of $13.8-273.16 \mathrm{~K}$ with the accuracy of $\pm(5-6) \mathrm{mK}$ after thermal stabilization and precise calibration and allowed to realize this possibility using the proposed mathematical descriptions and calibration method. The calibration is valid for at least 30 months (2.5 years) after their thermal stabilization and probably more.

The proposed three-point calibration method allows to apply them with the accuracy of $\pm 0.04 \Omega( \pm 0.1 \mathrm{~K}$ above $45 \mathrm{~K}$ and $\pm 0.3 \mathrm{~K}$ below $45 \mathrm{~K}$ ) for small quantities of TPRTs. Their accuracy can be better $( \pm 0.1 \mathrm{~K}$ in the whole range of $13.8-300 \mathrm{~K}$ ) when industrial quantities of sensors have to be calibrated.

The new developed least squares method is not specialized and allows to make an adequate mathematical description of any experimental results in an ordinary polynomial form. It ensures a higher physical authenticity of the fitted curve in comparison with the conventional least squares methods and the same results as OPEM [11] but it possesses some indisputable advantages. For this reason it can be recommended for practice.

\section{ACKNOWLEDGMENTS}

This work has been completed with the financial support of the National Foundation for Science Investigations under contract NoTH-627. The Authors wish to thank prof. I. Bivas and prof. B. Boyanov for the useful discussion on the mathematical problems of this paper.
[1] L. M. Besley, R. C. Kemp, Cryogenics 23, 26 (1983).

[2] R. C. Iye, Cryogenics 28, 164 (1988).

[3] D. A. Dimitrov, J. K. Georgiev, A. L. Zahariev, I. Bivas, Cryogenics 36, 599 (1996).

[4] A. L. Zahariev, D. A. Dimitrov, J. K. Georgiev, Cryogenics 36, 631 (1996).

[5] D. A. Dimitrov, B. M. Terzijska, V. Gevezov, V. T. Kovatchev, Cryogenics 30, 348 (1990).

[6] D. A. Dimitrov, A. L. Zahariev, J. K. Georgiev, G. A. Kolev, J. N. Petrinski, Tz. Ivanov, Cryogenics 34 , 478 (1994).

[7] W. H. Press, S. A. Teukolsky, W. T. Veterling, B. P. Flannery, Numerical Recipes (University Press, Cambridge, 1992).

[8] R. W. Hamming, Numerical Methods for Scientists and Engineers (Technika, Sofia, 1974).
[9] G. Forsythe, J. Soc. Industr. Appl. Mathem. 5, 263 (1957).

[10] M. Ascher, G. Forsythe, J. Assoc, Computing Mashinery 5, 9 (1958).

[11] V. Gadjokov, N. Bogdanova, JINR Commun. P11-12860 (1979), P11-80781 (1980), P11-80122 (1980), Dubna.

[12] N. Bogdanova, B. Terzijska, Rev. Sci. Instrum. 67, 3885 (1996).

[13] N. Bogdanova, B .Terzijska, Rev. Sci. Instrum. 68, 3766 (1997).

[14] H. Preston-Thomas, Metrologia 27, 3 (1990).

[15] E. Godratt, A. J. Greenfield, Y. Schlesinger, Cryogenics 17, 81 (1977).

[16] C. S. Cragoe, Proces-Verbaux Comite Intern. Poids et Mesures 21, T84 (1948). 


\section{СТІӤКІСТЬ ТА МЕТОДИ КАЛІБРУВАННЯ ДЕЯКИХ ТЕРМОМЕТРІВ НА ТОНКИХ ПЛАТИНОВИХ ПЛІВКАХ В ІНТЕРВАЛІ 13.8-273.16 К}

Й. К. Георгієв, Д. А. Димитров, А. Л. Захарієв Інститут фізики твердого тіла, Болгарсъка академія наук

72, Царіградско шосе, 1784, Софія, Болеарія

Стійкість опору термометрів на тонких металевих плівках, що виробляє фірма ПРІБОР, досліджували через 30 місяпів після ї температурної стабілізапї. Запропоновано триточковий метод калібрування для ділянки 18.8 K і 273.16 K. Визначено оптимальні умови, необхідні для адекватного індивідуального калібрування досліджених сенсорів. На підставі цього методу запропоновано математичні описи функцій $T(R) \mathrm{i}$ $R(T)$ між $13.8 \mathrm{~K}$ та $273.16 \mathrm{~K}$. 